J. Lake Sci. (湖泊科学), 2021, 33(6): 1871-1884

DOI 10. 18307/2021. 0621

(c) 2021 by Journal of Lake Sciences

\title{
长江中游城市群水资源承载力时空格局及耦合协调性
}

\author{
田 培 ${ }^{1,2 * *}$, 王瑾钰 ${ }^{1,2}$, 花 威 ${ }^{1,2}$, 郝芳华 ${ }^{2}$, 黄建武 ${ }^{1,2}$, 龚雨薇 ${ }^{1,2}$ \\ ( 1 : 华中师范大学地理过程分析与模拟湖北省重点实验室,武汉 430079) \\ ( 2 : 华中师范大学城市与环境科学学院,武汉 430079)
}

\begin{abstract}
摘 要: 长江中游城市群是实施生态优先绿色发展战略的重点区域, 从水资源承载系统内的水资源、社会、经济、生态环 境 4 个子系统中选取 24 项指标构建水资源承载力评价体系,综合运用改进摘权 TOPSIS 模型、空间自相关分析和耦合协 调发展模型定量评价 2012-2018 年长江中游城市群水资源承载力时空变化过程及子系统间的耦合协调性. 结果表明, (1) 长江中游城市群整体水资源承载力水平表现为: 缓慢上升 (2012- 2015 年)、下降 (2015-2017 年)、再上升的趋势 (2017-2018 年) ; (2) 水资源承载力的空间差异不明显 (仅 2016 年差异显著), 武汉城市圈水资源承载力的空间差异相 对较大且呈现低值包围高值的空间分布特征; (3) 各城市生态环境子系统承载力得分较为均衡, 但其他子系统的承载力 均差异较大; (4) 影响水资源承载力的主要因素依次为城市污水处理厂日处理能力、人均 GDP、城镇化率、第三产业比重 和人均水资源量; (5) 长江中游城市群水资源承载系统的耦合协调度总体处于中等水平, 且水资源承载力与耦合协调度 有极强的正相关关系. 研究结果可为长江中游城市群水资源承载力改善及水资源优化配置提供依据.
\end{abstract}

关键词: 水资源承载力;改进摘权法;时空格局;耦合协调度;长江中游城市群

\section{Temporal-spatial patterns and coupling coordination degree of water resources carrying capacity of urban agglomeration in the middle reaches of the Yangtze River *}

Tian Pei ${ }^{1,2 * *}$, Wang Jinyu ${ }^{1,2}$, Hua Wei ${ }^{1,2}$, Hao Fanghua ${ }^{2}$, Huang Jianwu ${ }^{1,2} \&$ Gong Yuwei $^{1,2}$ (1: Key Laboratory for Geographical Process Analysis \& Simulation Hubei Province, Wuhan 430079, P.R.China)

(2: College of Urban and Environmental Sciences, Central China Normal University, Wuhan 430079, P.R.China)

\begin{abstract}
The urban agglomeration in the middle reaches of the Yangtze River is a key area for implement the ecological priority green development strategy. This study selects 24 indicators from water resources subsystem, social subsystem, economic subsystem, and eco-environmental subsystem of the water resources carrying systemto construct a water resources carrying capacity evaluation system. The improved entropy weight TOPSIS model, spatial autocorrelation analysis and coupling coordination model are used to quantitatively evaluate the spatiotemporal process of water resources carrying capacity and the coupling coordination degree of the four subsystems in urban agglomeration in the middle reaches of the Yangtze River from 2012 to 2018. The results showed that, (1) The overall water resources carrying capacity of the urban agglomeration in the middle reaches of the Yangtze River shows a trend of slow increase (2012-2015), decrease (2015-2017), and rise again (2017-2018); (2) The spatial difference of water resources carrying capacity is not obvious (only behaving significant differences in 2016). The spatial difference of water resources carrying capacity of Wuhan Metropolitan Area is relatively significant and is characteristic of the spatial distribution characteristics of low values surrounding high values. (3) The carrying capacity of the eco-environmental subsystem of each city is relatively balanced, but the carrying capacity of other subsystems are quite different. (4) The main factors affecting the carrying capacity of water resources are daily treatment capacity of municipal wastewater treatment plants, GDP per capita, urbanization rate, proportion of tertiary industry and water resources per capita. (5) The coupling and coordination of water resources carrying systems in study
\end{abstract}

* 2021-03-17 收稿; 2021-04-18 收修改稿.

国家自然科学基金项目 (41907061)、黄土高原土壤侵蚀与早地农业国家重点实验室开放资金项目 (A3140214022005 ) 和长江科学院水利部山洪地质灾害防治工程技术研究中心研究基金项目 (CKWV2019761/KY)联合资助.

** 通信作者; E-mail:tianpei@ mail.ccnu.edu.cn. 
area is generally at a medium moderate level, and water resources carrying capacity is positive correlation with the (degree of) coupling coordination. The research results can provide a basis ground for the improvement of water resources carrying capacity and the optimal allocation of water resources in the urban agglomeration in the middle reaches of the Yangtze River.

Keywords: Water resources carrying capacity; improved entropy method; temporal-spatial patterns; coupling coordination degree; urban agglomeration in the middle reaches of the Yangtze River

经济社会的可持续发展与良好生态环境的维持必须考虑水资源承载力 ${ }^{[1-3]}$. 水资源承载力的定义大体 可分为两类,一类是在可持续发展的前提下, 水资源能够支撑的最大人口和社会经济规模 ${ }^{[4-6]}$; 另一类是通 过对水资源的合理配置, 达到水资源、经济社会和生态环境之间的协调发展 ${ }^{[7-9]}$. 本文认为水资源承载力是 以可持续发展为原则,在满足生态环境用水的前提下,水资源对经济社会可持续发展的支撑能力. 水资源承 载力评价方法多样, 包括系统动力学法、多目标分析法和综合评价法等 ${ }^{[10]}$. Wang 等 ${ }^{[11]}$ 采用突变级数法对 2010－2016 年中国跨省水资源综合承载力进行了评价; Wu 等 ${ }^{[12]}$ 运用 MPCA 与风险矩阵的耦合模型对 2005-2015 年安徽省水资源承载力进行了评价; Fang 等 ${ }^{[13]}$ 利用二元指数法和约简指数法对太湖流域水资 源承载力进行了评价; 张礼兵等 ${ }^{[14]}$ 基于系统动力学对巢湖流域水资源承载力进行了动态预测与调控研究. 水资源承载系统是一个多目标决策系统, 由水资源、社会、经济和生态环境子系统耦合组成 ${ }^{[15-17]}$, 因而在水 资源承载力研究中, 必须考虑各子系统间的协调发展水平. 协调度是定量描述区域范围内各要素或系统间 协调状况程度的指标, 通常由耦合协调发展模型计算得出 ${ }^{[18-19]}$. 王保乾等 ${ }^{[15]}$ 运用 4 系统耦合协调度模型衡 量了长江经济带水资源、社会、经济和生态子系统的协调发展关系. Wang 等 ${ }^{[20]}$ 运用 3 系统耦合协调模型测 算了湖南省水资源、社会经济、生态环境系统间的耦合协调度.

长江中游城市群是长江流域人口最密集、水资源开发利用强度最高、生态环境问题最严峻的地区之 一 $^{[21]}$. 近年来, 该地区水资源承载力的研究得到广泛关注. 姜大川等 ${ }^{[22]}$ 运用单位 GDP 综合用水量评判法计 算了武汉城市圈的水资源承载力; 熊鹰等 ${ }^{[23]}$ 基于双要素水资源承载力模型的评价结果表明, 长株潭城市群 2003－2012 年水资源濒临超载, 2013-2019 年属于水质型超载; 危文广等 ${ }^{[24]}$ 运用理想点法得出江西省水资 源承载力从 2011-2015 年整体呈上升趋势. 总体而言, 这些研究对长江中游地区水资源承载力时空格局研 究不够深人, 没有探讨水资源承载系统内部的耦合协调度; 另外, 评价主体主要是相关省份或内部小城市 群 $^{[22-26]}$, 以长江中游城市群整体为对象的研究多集中在生态承载力 ${ }^{[27-29]}$ 和绿色发展水平 ${ }^{[30-32]}$ 上, 而水资源 承载力时空演变及耦合协调性的研究鲜见报道.

2015 年 4 月, 《长江中游城市群发展规划》 ${ }^{[33]}$ 印发, 长江中游城市群是长江经济带实施生态优先绿色发 展战略的重点区域, 研究其水资源承载力时空变化以及水资源、社会、经济、生态环境系统间耦合协调程度 具有重要意义. 本文选取 2012-2018 年(涵盖规划印发前后各 3 年) 为研究时段,对长江中游城市群及其所 含 28 个城市的水资源承载力进行综合评价,深人分析水资源承载力时空格局及其影响机制、水资源承载系 统的耦合协调关系, 以期为促进该区域水资源可持续利用、经济社会发展与生态环境保护相协调提供理论 依据.

\section{1 研究区概况}

长江中游城市群是以武汉城市圈、环长株潭城市群、环鄱阳湖城市群为主体的特大型城市群, 是长江经 济带的重要组成部分, 共包括 31 个城市 ${ }^{[33]}$ (图 1). 2017 年长江中游城市群的经济总量为 7.9 万亿元、人口 总量为 1.53 亿、土地面积为 31.7 万 $\mathrm{km}^{2}$, 分别占全国的 $9.6 \% 、 11.1 \%$ 和 $3.3 \%{ }^{[27]}$. 长江中游城市群水资源总 体上非常丰富,拥有鄱阳湖、洞庭湖、汉江、清江等众多江河湖泊; 但作为鄂湘赣三省的人口和社会经济发展 集聚区,近年来重化工业过度集聚和粗放低效的资源利用方式使得水资源消耗量和污水排放量都非常 $大^{[34]}$, 且鄱阳湖、洞庭湖、洪湖等重点湖泊富营养化加剧、水环境容量降低等问题逐渐凸显, 总体上该区域的 水资源承载压力和水生态安全问题较为突出 ${ }^{[28]}$. 


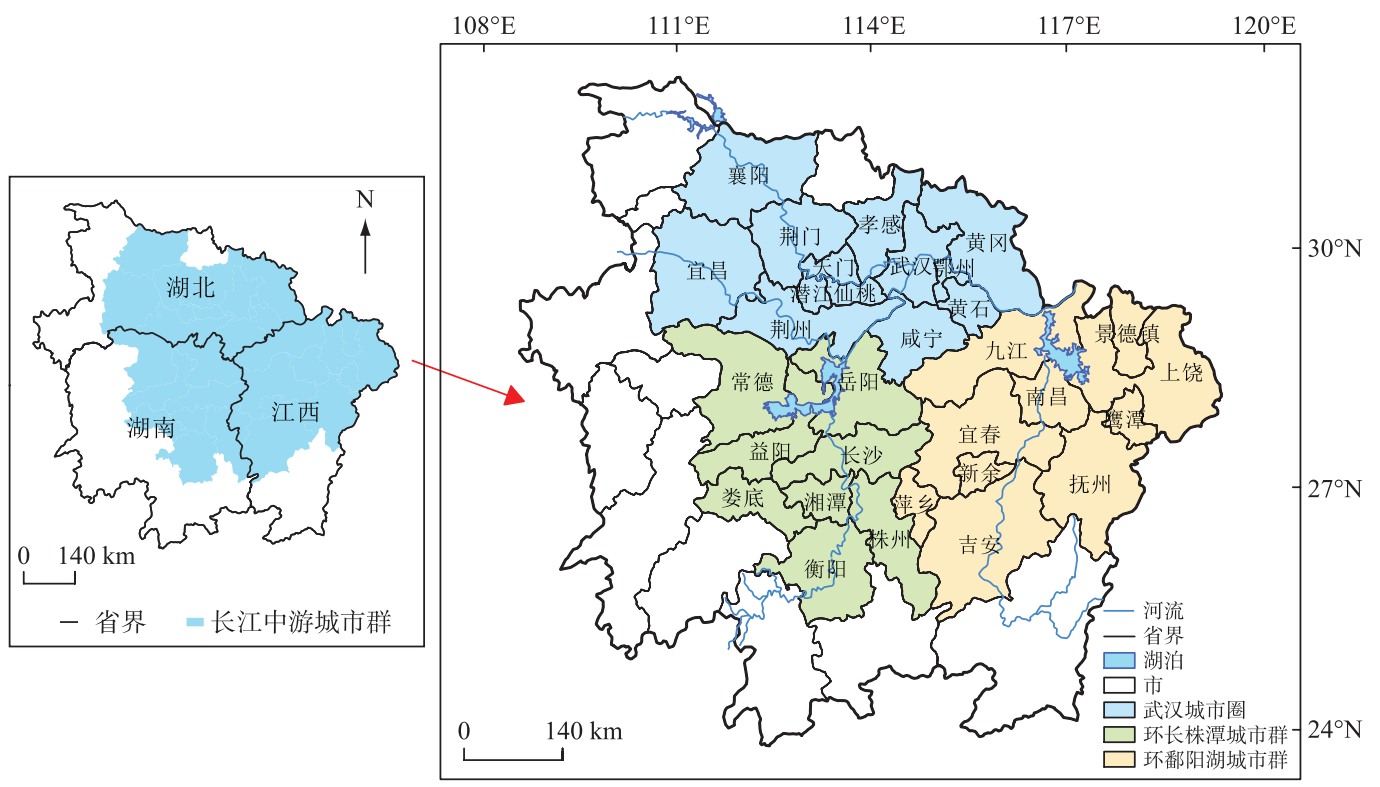

图 1 长江中游城市群示意

Fig.1 Urban agglomeration in the middle reaches of the Yangtze River

\section{2 研究方法}

\section{1 水资源承载力评价指标体系构建及数据来源}

水资源承载力评价指标体系的构建要体现水资源、社会、经济、生态环境 4 个子系统及其相互关系,并 遵循科学性、客观性、代表性和数据可获得性等原则. 综合已有成果, 从水资源、社会、经济、生态环境 4 个系 统出发建立评价指标体系 ${ }^{[15,35]}$, 选择使用频率较高的指标. 在水资源子系统内, 从水资源数量、水资源开发 利用两个维度中选取 6 项指标 ${ }^{[36-37]}$; 在社会子系统内, 从社会发展水平、用水需求两个维度中选取 6 项指 标; 在经济子系统内, 从经济发展水平、用水效率两个维度中选取 6 项指标 ${ }^{[35]}$; 在生态环境子系统内, 从生态 环境状况、生态环境治理两个维度中选取 6 项指标 ${ }^{[36,38]}$, 建立了长江中游城市群水资源承载力评价指标体 系,如表 1 所示.

水资源子系统所含指标数据来源于 2012-2018 年湖北、湖南、江西省《水资源公报》; 社会与经济子系 统所含指标数据来源于湖北、湖南、江西 3 省及相关地级市的《统计年鉴》、《国民经济与社会发展统计公 报》、《水资源公报》及《水土保持公报》; 生态环境子系统所含指标数据来源于《中国城市统计年鉴》各地市 《环境质量公报》. 湖北省仙桃、潜江、天门 3 个县级市相关数据获取难度较大、缺失较多,鉴于 3 市人口、 GDP 和水资源总量分别仅占长江中游城市群的 $2.59 \% 、 2.52 \%$ 和 $1.75 \%$, 故未将这 3 市纳人评价范围. 江西 省吉安市仅部分县 ( 区) 属于长江中游城市群, 基于数据可获取性及准确性原则, 以吉安全市统计数据为依 据进行计算.

\section{2 改进熵权 TOPSIS 模型}

2.2.1 改进的摘权法 熵权法根据不同指标数据的离散程度确定指标权重,能够有效避免人为主观因素的干 扰, 属于客观赋权方法 ${ }^{[38]}$. 本文指标数据是基于行政单元统计的水资源、社会、经济和生态环境数据, 指标 权重采用熵权法确定. 传统熵权法在计算熵值趋向于 1 的指标权重时, 熵值的微小差异会引起权重成倍变 化, 致使部分指标获得了与其重要性不相符的权重 ${ }^{[39]}$, 不少学者针对这个问题进行了改进 ${ }^{[40-42]}$. 其中, 李英 海和周建中 ${ }^{[41]}$ 的改进熵权法既克服了传统熵权法的不足, 又保留了指标权重拉开差距的能力, 故本文借鉴 此方法计算指标权重,步骤如下: 
表 1 长江中游城市群水资源承载力评价指标体系

Tab.1 Evaluation index system of water resources carrying capacity of urban agglomeration in the middle reaches of the Yangtze River

\begin{tabular}{|c|c|c|c|c|c|c|}
\hline \multicolumn{2}{|c|}{ 目标 准则 } & 维度 & 指标 & 计算方法 & 指标意义 & 类型 \\
\hline \multirow{24}{*}{$\begin{array}{l}\text { 水 } \\
\text { 资 } \\
\text { 源 } \\
\text { 承 } \\
\text { 载 } \\
\text { 力 }\end{array}$} & \multirow{6}{*}{$\begin{array}{l}\text { 水 } \\
\text { 资 } \\
\text { 源 } \\
\text { 系 } \\
\text { 统 }\end{array}$} & 水资源数量 & 人均水资源量 $\mathrm{C} 1$ & 水资源总量/常住人口总量 & 反映水资源人均拥有量情况 & 正 \\
\hline & & & 地表水资源占比 C2 & 地表水资源量/水资源总量 & 反映水资源的丰枯状况 & 正 \\
\hline & & & 产水模数 C3 & 水资源总量/区域面积 & 反映区域单位面积产水能力 & 正 \\
\hline & & 水资源开发利用 & 人均水资源利用量 C4 & 用水量/常住人口总量 & 反映水资源人均利用状况 & 负 \\
\hline & & & 供水模数 C5 & 供水量/区域面积 & 反映区域单位面积供水能力 & 负 \\
\hline & & & 水资源开发利用率 C6 & 供水量/水资源总量 & 反映水资源的开发利用程度 & 负 \\
\hline & \multirow{6}{*}{$\begin{array}{l}\text { 社 } \\
\text { 会 } \\
\text { 系 } \\
\text { 统 }\end{array}$} & 社会发展水平 & 人口密度 C7 & 区域总人口/区域面积 & 反映人口密集程度 & 负 \\
\hline & & & 人口自然增长率 $\mathrm{C} 8$ & 统计数据 & $\begin{array}{l}\text { 反映人口增长对水资源的动态 } \\
\text { 压力 }\end{array}$ & 负 \\
\hline & & & 城镇化率 C9 & 城镇常住人口/常住总人口 & 反映城镇化水平 & 正 \\
\hline & & & 居民消费价格指数 C10 & 统计数据 & 反映居民生活水平 & 正 \\
\hline & & 用水需求 & 城市人均日生活用水量 C11 & 统计数据 & 反映城市居民人均用水情况 & 负 \\
\hline & & & 人均耕地面积 $\mathrm{C} 12$ & 耕地面积/常住人口总量 & $\begin{array}{l}\text { 反映水资源与区域环境的协调 } \\
\text { 状态 }\end{array}$ & 正 \\
\hline & & 经济发展水平 & 第三产业比重 C13 & 统计数据 & 反映地区经济结构优化程度 & 正 \\
\hline & & & 人均 GDP C14 & 统计数据 & 反映地区经济发展水平 & 正 \\
\hline & & & GDP 增长率 $\mathrm{C} 15$ & 统计数据 & 反映地区经济发展能力 & 正 \\
\hline & & 用水效率 & 万元 GDP 用水量 C16 & 用水总量/GDP 总量 & $\begin{array}{l}\text { 反映水资源与经济发展的协 } \\
\text { 调度 }\end{array}$ & 负 \\
\hline & & & 农田亩均灌溉用水 C17 & 统计数据 & 反映农业生产用水效率 & 负 \\
\hline & & & 万元工业增加值用水量 C18 & 工业用水量/工业增加值 & 反映工业用水效率 & 负 \\
\hline & \multirow{6}{*}{$\begin{array}{l}\text { 生 } \\
\text { 态 } \\
\text { 环 } \\
\text { 境 } \\
\text { 系 } \\
\text { 统 }\end{array}$} & 生态环境状况 & 建成区绿化覆盖率 C19 & 统计数据 & 反映城市绿化程度 & 正 \\
\hline & & & $\begin{array}{l}\text { 河流达到或好于 III 类水体的比 } \\
\text { 例 } \mathrm{C} 20\end{array}$ & 统计数据 & 反映区域生态的优化程度 & 正 \\
\hline & & & 人均工业废水排放量 C21 & 工业废水排放量/常住人口总量 & 反映工业废水对环境的影响 & 负 \\
\hline & & & $\begin{array}{l}\text { 水土流失面积占国土面积比 } \\
\text { 例 C22 }\end{array}$ & 水土流失面积/国土面积 & 反映区域水土流失情况 & 负 \\
\hline & & 生态环境治理 & 生态环境用水率 C23 & 生态环境用水量/水资源总量 & 反映生态环境的保护程度 & 负 \\
\hline & & & $\begin{array}{l}\text { 城市污水处理厂日处理能 } \\
\text { 力 } 224\end{array}$ & 统计数据 & 反映污水的处理能力 & 正 \\
\hline
\end{tabular}

1) 数据标准化. 设研究区水资源承载力评价的原始数据矩阵 $\left(Z_{i j}\right)$ 为:

$$
Z_{i j}=\left[\begin{array}{cccc}
z_{11} & z_{12} & \cdots & z_{1 n} \\
z_{21} & z_{22} & \cdots & z_{2 n} \\
\vdots & \vdots & \vdots & \vdots \\
z_{m 1} & z_{m 2} & \cdots & z_{m n}
\end{array}\right]
$$

式中, $m$ 为评价城市的数量, $n$ 为评价指标总数.

因数据的量纲不一, 要先标准化数据. 指标数据正、负向之分, 正向指标表示指标值越大越好, 负向指标 表示指标值越小越好,采用极差法进行数据标准化:

$$
\begin{aligned}
& A_{i j}=\left(z_{i j}-\min z_{i}\right) /\left(\max z_{i}-\min z_{i}\right) \\
& A_{i j}=\left(\max z_{i}-z_{i j}\right) /\left(\max z_{i}-\min z_{i}\right)
\end{aligned}
$$

式中, $z_{i j}(i=1,2, \cdots, m ; j=1,2, \cdots, n)$ 为第 $i$ 个城市的第 $j$ 个指标值.

2) 计算第 $i$ 城市第 $j$ 项指标值在所有城市中所占的比重 $\left(P_{i j}\right)$, 即: 


$$
P_{i j}=x_{i j} / \sum_{i=1}^{m} x_{i j}
$$

3 ) 计算各指标的熵值 $\left(H_{j}\right)$, 即:

$$
H_{j}=-\frac{1}{\ln (m)} \sum_{i=1}^{m} P_{i j} \ln P_{i j} \quad(j=1,2, \cdots, n)
$$

4) 计算各指标的熵权系数 $\left(\omega_{\mathrm{j}}\right)$, 即:

$$
\omega_{j}=\left\{\begin{array}{l}
(1-\bar{H}) \omega_{0 j}+\bar{H} \omega_{3 j}, H_{j}<1 \\
0, H_{j}=1
\end{array}\right\}
$$

式中, $\omega_{j}$ 表示第 $j$ 个指标的权重; $H_{j}$ 是第 $j$ 个指标的熵值; $\bar{H}$ 是所有不为 1 的熵值的平均值.

$$
\omega_{0 j}=\frac{1-H_{j}}{\sum_{j=1}^{n}\left(1-H_{j}\right)}, \omega_{3 j}=\frac{1+\bar{H}-H_{j}}{\sum_{k=1, H_{i} \neq 1}^{n}\left(1+\bar{H}-H_{k}\right)}
$$

熵权系数 $\omega_{j}$ 越大,则该指标代表的信息量越大, 对综合评价的作用越大.

2.2.2 TOPSIS 模型 TOPSIS 模型是一种逼近理想解的评价方法, 以各个城市为评价对象, 通过计算各对象 与理想解的贴进度 $C$ 来进行评价, $C$ 取值在 $[0,1]$ 之间, 与理想解越近, 值越接近 1 , 评价结果越好 ${ }^{[43-45]}$. 借 鉴已有研究成果 ${ }^{[46-47]}$, 将水资源承载力水平分为 5 个等级,如表 2 所示.

表 2 水资源承载力分级标准

Tab.2 Water resources carrying capacity grading standard

\begin{tabular}{cccccc}
\hline 贴进度 $C$ & {$[0,0.3)$} & {$[0.3,0.4)$} & {$[0.4,0.5)$} & {$[0.5,0.6)$} & {$[0.6,1]$} \\
\hline 等级 & $\mathrm{V}$ & $\mathrm{IV}$ & $\mathrm{III}$ & $\mathrm{II}$ & $\mathrm{I}$ \\
内涵 & 水资源匮乏 & 水资源短缺 & 水资源合理 & 水资源协调 & 水资源充裕 \\
\hline
\end{tabular}

\section{3 空间自相关}

空间自相关分析能够揭示某区域数据与邻近区域数据间是否具有关联性,包括全局空间自相关和局部 空间自相关 ${ }^{[48-49]}$, 前者考察研究区是否存在空间聚集现象、用于分析区域总体的空间关联和差异程度,而后 者考察研究区内某区域与相邻区域的空间集聚程度. 借助 Geoda1.16 软件计算长江中游城市群水资源承载 力全局 Moran's $I$ 指数和局部 Moran's $I$ 指数并生成 LISA 聚类地图, 以揭示该地区水资源承载力的空间分异 情况.

\section{4 耦合协调发展模型}

为了对水资源子系统、社会子系统、经济子系统和生态环境子系统的耦合协调程度进行分析, 参考相关 研究成果 ${ }^{[15,19]}$, 构造耦合协调度函数如下:

$$
A=\left\{X_{1} \times X_{2} \times X_{3} \times X_{4} /\left[\left(X_{1}+X_{2}+X_{3}+X_{4}\right) / 4\right]^{4}\right\}^{1 / 4}
$$

式中, $A$ 为耦合度; $X_{1} 、 X_{2} 、 X_{3} 、 X_{4}$ 分别代表水资源子系统、社会子系统、经济子系统、生态环境子系统的承载 力,由各子系统评价指标的取值乘以其权重得到.

$$
\begin{gathered}
D=\sqrt{A \times T} \\
T=\alpha X_{1}+\beta X_{2}+\gamma X_{3}+\lambda X_{4}
\end{gathered}
$$

式中, $D$ 为耦合协调度; $T$ 为四元系统的综合评价值; $\alpha 、 \beta 、 \gamma 、 \lambda$ 表示待定系数,一般认为在水资源承载系统 中,水资源子系统、社会子系统、经济子系统、生态环境子系统同等重要,故取 $\alpha=\beta=\gamma=\lambda=1 / 4$.

\section{3 结果与分析}

\section{1 水资源承载力的时间变化特征}

运用改进熵权法结合 TOPSIS 模型, 计算出长江中游城市群 28 个城市的水资源承载力指数并取平均值 得到长江中游城市群整体的水资源承载力水平; 长江中游城市群所含的武汉城市圈、环长株潭城市群、环鄱 阳湖城市群的水资源承载力同理可得,如图 2 所示. 


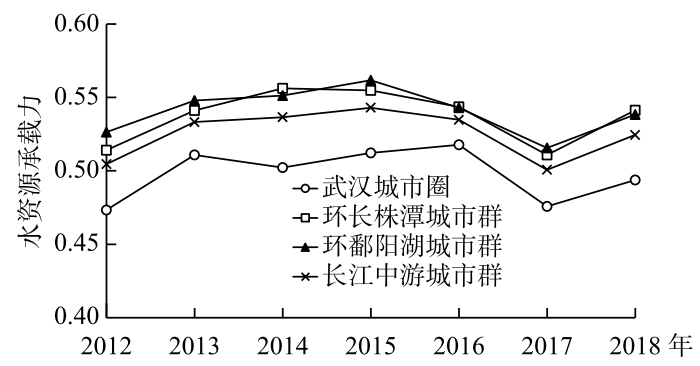

图 2 2012-2018 年长江 中游城市群水资源承载力变化趋势

Fig. 2 Trend of water resources carrying capacity in urban agglomeration in the middle reaches of the Yangtze River from 2012 to 2018

在评价时段内, 水资源承载力总体呈先缓慢上 升后下降再上升的波动变化趋势. 环长株潭城市 群、环鄱阳湖城市群以及长江中游城市群各年水资 源承载力得分均超过 0.5 ,处于水资源协调状态, 其 中, 环鄱阳湖城市群承载力于 2015 年达到最高值 (0.562). 武汉城市圈水资源承载力水平低于其他 2 个城市群和长江中游城市群整体, 2012、2017、2018 年承载力得分低于 0.5 , 处于合理状态. 水资源承载 力评分均在 2017 年出现最小值, 为究其原因, 选择 波动显著的 3 年 (2016-2018 年) 分析指标的标准 化加权值, 如图 3(横坐标代表长江中游城市群 28 个城市) 所示, 可以发现地表水资源占比 (C2)、人口 自然增长率 (C8)、人均耕地面积 ( C12) 指标在 2017 年的数值显著低于 2016 和 2018 年; 地表水资源占 比反映水资源的丰枯, 人口自然增长率和人均耕地 面积反映人口动态变化和水资源与区域环境的协调状态, 说明水资源禀赋及人口增长对水资源的压力是限 制长江中游城市群水资源承载力提升的重要因素.

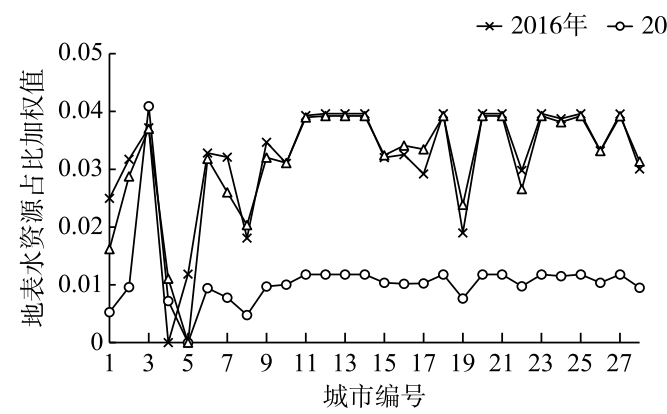

成市编号
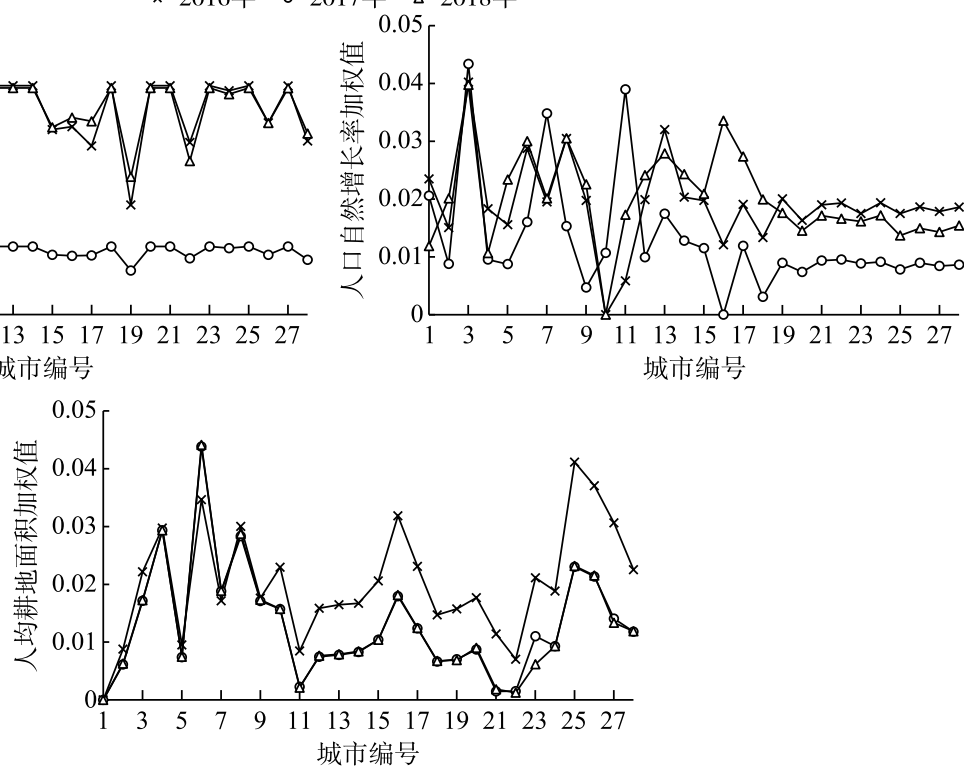

图 3 2016-2018 年部分水资源承载力指标加权值

（编号 1 28 分别代表武汉、黄石、宜昌、襄阳、鄂州、荆门、孝感、荆州、黄冈、咸宁、长沙、株洲、湘潭、 衡阳、岳阳、常德、益阳、娄底、南昌、景德镇、萍乡、九江、新余、鹰潭、吉安、宜、春、抚州、上饶）

Fig.3 Apart of the weighted value of evaluation indices from 2016 to 2018

\section{2 水资源承载力的空间格局演化}

3.2 .1 空间分布特征 利用 ArcGIS10.2 绘制 2012-2018 年各城市水资源承载力空间分布图 (图 4), 水资源 承载力水平整体较高, 得分集中在合理、协调、充裕三级. 2012-2016 年, 长江中游城市群水资源承载力水平 整体呈上升趋势, 至 2016 年最高; 其中, 3 个城市承载力处于丰裕状态, 4 个城市处于合理状态, 其余城市处 于协调状态. 2017、2018 年承载力水平整体相对降低, 出现了水资源短缺状态, 空间差异增大. 武汉城市圈 
2012-2018 年 10 个城市的水资源承载力评分均值为 0.498 ,较环长株潭城市群 (0.537) 和环鄱阳湖城市群 $(0.541)$ 低. 长沙、宜昌、武汉水资源承载力评分最高, 7 年平均得分依次为 $0.611 、 0.587 、 0.579$, 水资源较为充 裕. 黄石、孝感、鄂州水资源承载力评分最低, 分别为 $0.460 、 0.454 、 0.408$, 其中鄂州水资源承载力于 2017 、 2018 年降至短缺等级. 分析鄂州市原始数据可知, 2017、2018 年人均水资源量较 2016 年分别下降了 $58.5 \%$ 和 $66.6 \%$, 产水模数分别下降了 $58.1 \%$ 和 $66.3 \%$, 水资源禀赋条件欠佳导致鄂州水资源承载力的降低.
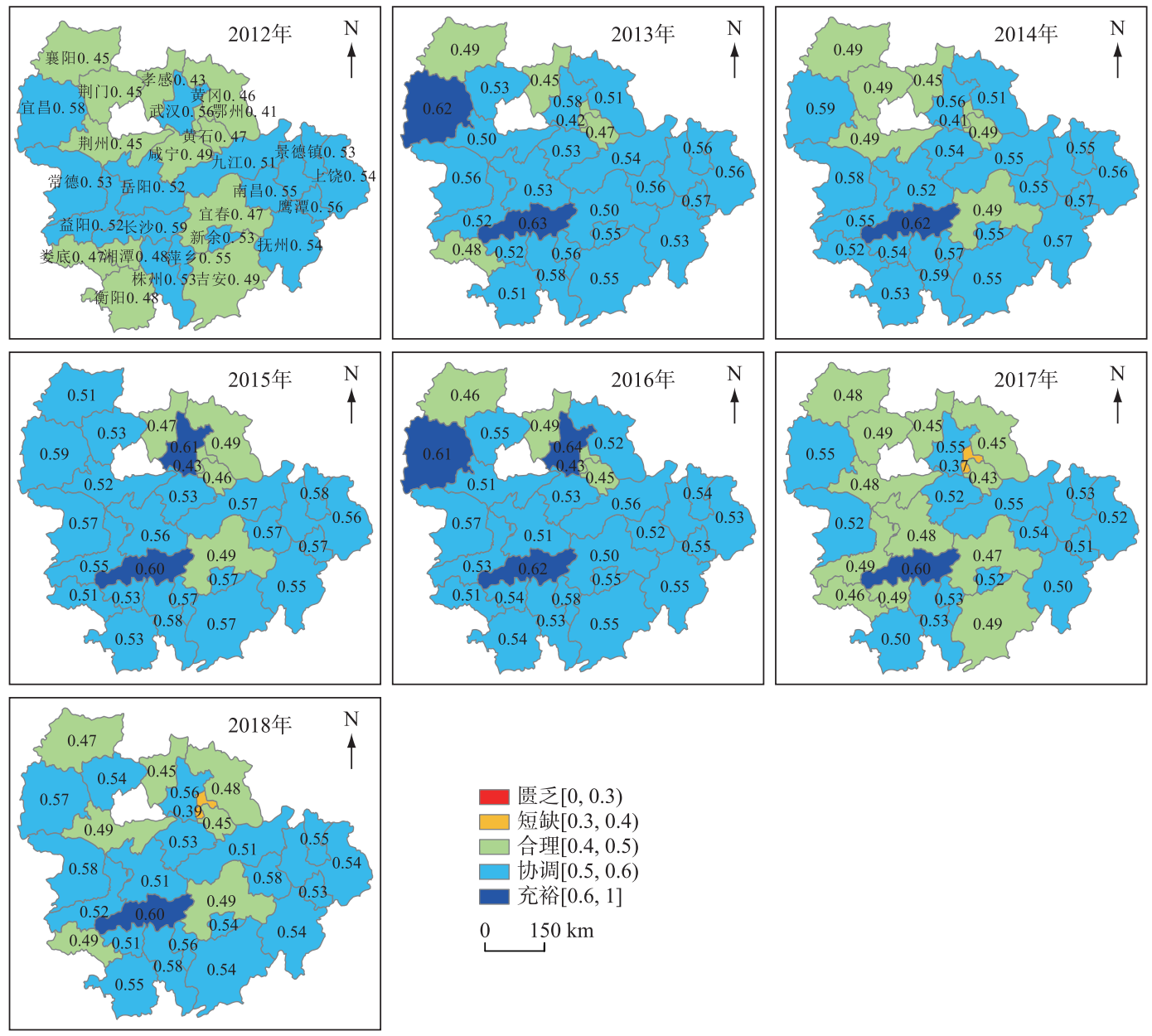

图 4 2012-2018 年长江中游城市群水资源承载力空间分布

Fig.4 Spatial different of water resources carrying capacity inurban agglomeration in the middle reaches of the Yangtze River from 2012 to 2018

3.2.2 空间自相关分析 借助 Geoda1.16 软件构造空间权重矩阵, 获得长江中游城市群水资源承载力 20122018 年全局自相关 Moran's $I$ 指数 (表 3). 在 0.1 的置信水平上, 2016 年全局 Moran's $I$ 指数为 $-0.237, P$ 值为 0.051 (<0.1), 通过了显著性检验, 说明 2016 年长江中游城市群呈现较为显著的空间异质格局.

基于研究区 2012-2018 年的局部 Moran's I 指数得到 LISA 聚类地图 (图 5),局部空间自相关 LISA 聚集 类型主要包括低一高、高一低、低一低 3 种类型. 2012 年宜春、2016 年九江、以及研究年限内武汉均为高一低模 式, 这 3 个城市的水资源承载力高而临近地区的水资源承载力低, 为高值异质中心; 2012、2015、2017 年宜春 以及 2016 年荆州为低一高模式, 水资源承载力低而临近地区水资源承载力高, 为低值异质中心 ; 2012- 2015 年、2018 年黄冈为低一低模式, 为低值聚集中心. 武汉城市圈呈现明显的低值包围高值的空间分布特征, 表 
表 3 2012-2018 年长江中游城市群水资源承载力全局自相关 Moran's $I$ 指数

Tab.3 Moran's $I$ of water resources carrying capacity in urban agglomeration in the middle reaches of the Yangtze River from 2012 to 2018

\begin{tabular}{cccccccc}
\hline & 2012 年 & 2013 年 & 2014 年 & 2015 年 & 2016 年 & 2017 年 & 2018 年 \\
\hline Moran's $I$ & 0.010 & -0.042 & 0.128 & 0.015 & -0.237 & 0.009 & 0.052 \\
$P$ & 0.337 & 0.500 & 0.091 & 0.320 & 0.051 & 0.353 & 0.215 \\
\hline
\end{tabular}

现出明显的空间差异. 其他地区聚集性和异质聚集性不明显, 空间差异较小. 总体而言, 2012- 2018 年长江 中游城市群水资源承载力的空间差异呈先缩小、再增大、后缩小趋势, 武汉城市圈水资源承载力较其他 2 个 城市群低且空间差异大, 主要由于武汉城市圈内部社会经济发展不平衡, 而其他 2 个城市群得益于其良好 的水资源禀赋,水资源承载力相对较高, 内部差异较小.
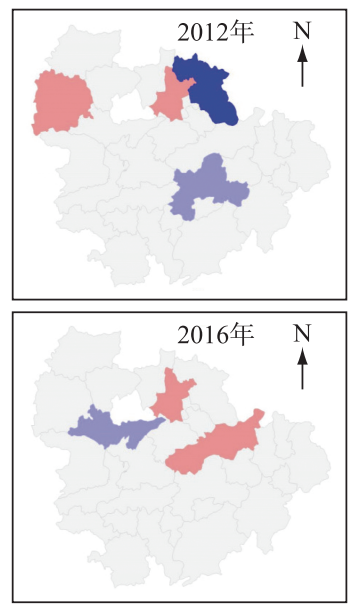


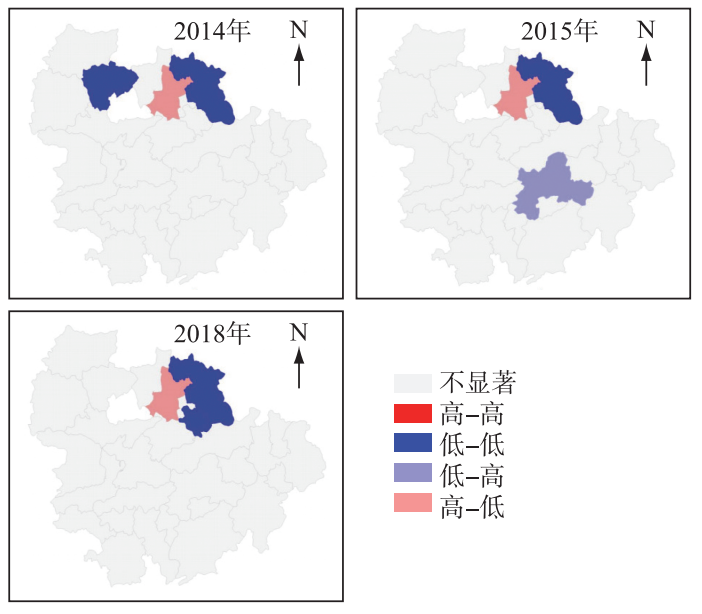

图 5 2012-2018 年长江中游城市群水资源承载力 LISA 聚类地图

Fig.5 LISA cluster map of water resources carrying capacity in urban agglomeration in the middle reaches of the Yangtze River from 2012 to 2018

\section{3 子系统差异性评价}

水资源承载系统由水资源子系统、社会子系统、经济子系统、生态环境子系统组成, 对水资源承载力各 子系统进行了评价,结果如图 6 所示.

各城市水资源子系统评分差异较大. 上饶、抚州、景德镇评分最高, 平均评分为 $0.829 、 0.821$ 和 0.795 , 均 位于环鄱阳湖城市群 (图 6). 武汉城市圈的孝感、襄阳、鄂州评分最低, 平均评分依次为 $0.420 、 0.406$ 和 0.108. 武汉城市圈水资源子系统承载力 (0.497) 较环长株潭城市群 (0.613)、环鄱阳湖城市群 $(0.724)$ 低且内 部差异大. 对比 3 个城市群 2012-2018 年水资源子系统标准化后的数据, 发现武汉城市圈 12 个城市平均后 的所有指标数据均小于其他 2 个城市群, 因此造成武汉城市圈水资源子系统承载力较低. 长江中游城市群 各个城市的社会子系统承载力均处于合理及以上等级. 评分最高的 3 个城市 (荆门、宜昌、荆州) 和评分最低 的 3 个城市 (咸宁、鄂州、黄冈) 均位于武汉城市圈, 该地区社会子系统承载力差异较大, 而环长株潭城市群、 环鄱阳湖城市群评分分布较为均衡. 经济子系统承载力评分差异悬殊, 武汉、长沙、南昌评分最高, 平均评分 为 $0.884 、 0.726 、 0.607$, 取权重第二大的人均 GDP 指标标准化后数据的 7 年平均值, 排名前 4 的为武汉、长 沙、新余、南昌, 成为导致武汉、长沙、南昌评分最高的主要原因, 该结果也体现了长江中游城市群内省会城 市独大的特点. 评分最低的 3 个城市为抚州、吉安和宜春, 均位于环鄱阳湖城市群, 说明其社会经济子系统 承载力较武汉城市圈和环长株潭城市群低, 也反映出该城市群的经济发展水平相对落后. 长江中游城市群 
面积广阔, 内部各城市经济发展水平差异大,武汉、 长沙、南昌的经济实力相对较强但辐射能力较弱, 对城市群内其他城市发展的带动能力不强,造成社 会经济子系统承载力评分不均衡. 生态环境子系统 承载力评分较为均衡, 承载力整体较高, 各个城市 平均分皆在 0.4 以上. 最高值出现在武汉 $(0.589)$, 最低值出现在宜昌 $(0.439)$, 武汉城市圈 $(0.488)$ 评 分虽较环长株潭城市群 (0.599) 和环鄱阳湖城市群 (0.630) 低,但仍处于合理状态. 计算出长江中游城 市群 28 个城市的各个子系统承载力评分并取平均 值, 发现各个子系统承载力差异不大, 水资源子系 统、社会子系统、经济子系统和生态环境子系统承 载力分别为 $0.611 、 0.487 、 0.517$ 和 0.509 . 长江中下 游地区河川径流节律的变化是中下游生态环境面 临的主要问题之一, 通过降低水利水电工程的影响 进行生态修复后 ${ }^{[50]}$, 水资源承载力应会有所提升.

\section{4 子系统耦合协调度}

计算水资源承载系统的水资源、社会、经济、生 态环境子系统的耦合协调度, 并利用 ArcGIS 自然断 点法将其分为 5 个等级: 协调度极低 (0.596 $0.597)$ 、协调度较低 $(0.598 \sim 0.701)$ 、协调度中等

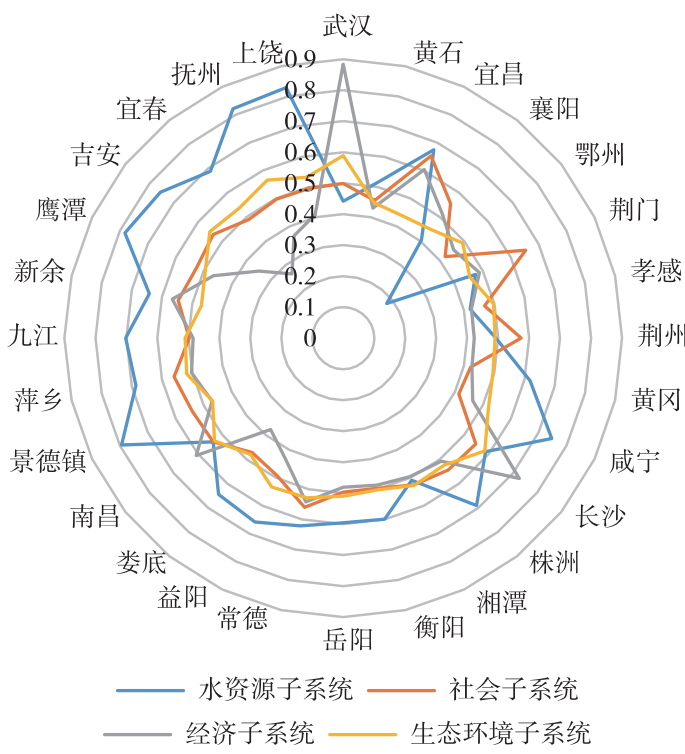

图 6 2012-2018 年水资源承载力子系统平均评分

Fig.6 Average score of water resources carrying capacity subsystem from 2012 to 2018

( $0.702 \sim 0.725)$ 、协调度较高 $(0.726 \sim 0.750)$ 、协调度极高 $(0.751 \sim 0.779), 28$ 个城市 $2012-2018$ 年平均耦合 协调度如表 4 所示.

表 4 长江中游城市群各个城市耦合协调度

Tab.4 Coordination degree among cities inurban agglomeration in the middle reaches of the Yangtze River

\begin{tabular}{|c|c|c|c|c|c|c|c|c|c|c|c|}
\hline 城市 & 评分 & 等级 & 城市 & 评分 & 等级 & 城市 & 评分 & 等级 & 城市 & 评分 & 等级 \\
\hline 武汉 & 0.762 & 极高 & 荆州 & 0.701 & 较低 & 岳阳 & 0.720 & 中等 & 九江 & 0.736 & 较高 \\
\hline 黄石 & 0.678 & 较低 & 黄冈 & 0.694 & 较低 & 常德 & 0.749 & 较高 & 新余 & 0.743 & 较高 \\
\hline 宜昌 & 0.764 & 极高 & 咸宁 & 0.722 & 中等 & 益阳 & 0.722 & 中等 & 鹰潭 & 0.744 & 较高 \\
\hline 襄阳 & 0.690 & 较低 & 长沙 & 0.779 & 极高 & 娄底 & 0.695 & 较低 & 吉安 & 0.725 & 中等 \\
\hline 鄂州 & 0.596 & 极低 & 株洲 & 0.749 & 较高 & 南昌 & 0.742 & 较高 & 宜春 & 0.684 & 较低 \\
\hline 荆门 & 0.714 & 中等 & 湘潭 & 0.717 & 中等 & 景德镇 & 0.744 & 较高 & 抚州 & 0.734 & 较高 \\
\hline 孝感 & 0.670 & 较低 & 衡阳 & 0.720 & 中等 & 萍乡 & 0.750 & 较高 & 上饶 & 0.739 & 较高 \\
\hline
\end{tabular}

长沙、宜昌、武汉耦合协调度极高. 长沙水资源承载力各子系统评分均在 0.5 以上;宜昌水资源、社会、经 济子系统承载力大于 0.6 , 弥补了生态环境子系统的短板 $(0.439)$; 武汉经济子系统评分为 0.884 , 水资源、社 会、生态环境子系统得分分别为 $0.442 、 0.499 、 0.589$, 可见社会经济的发展带来的节水减排技术可以提高水 资源利用效率和效益. 鄂州耦合协调度极低, 主要由于其水资源子系统承载力评分极低 $(0.180)$ 造成整体协 调度不高. 分析鄂州市标准化后的数据发现,除 2016 年产水模数 (C3) 指标外, 2012-2018 年鄂州水资源子 系统内 6 个指标数据均小于长江中游城市群平均值, 其中, 人均水资源利用量 (C4) 和供水模数 (C5) 的值 7 年间均为最小,地表水资源占比 (C2) 数据除 2016 年外为最小, 水资源开发利用率( C6) 数据除 2012 年、2016 年外为最小, 导致水资源子系统承载力评分低. 另外还有 10 个城市协调度较高, 7 个城市协调度中等、7个 城市协调度较低, 长江中游城市群水资源承载力子系统耦合协调度整体处于中等水平. 长沙、宜昌、武汉 2012-2018 年平均水资源承载力和耦合协调度在 28 个城市中处于前 3 位; 黄石、孝感、鄂州处于后 3 位, 通 


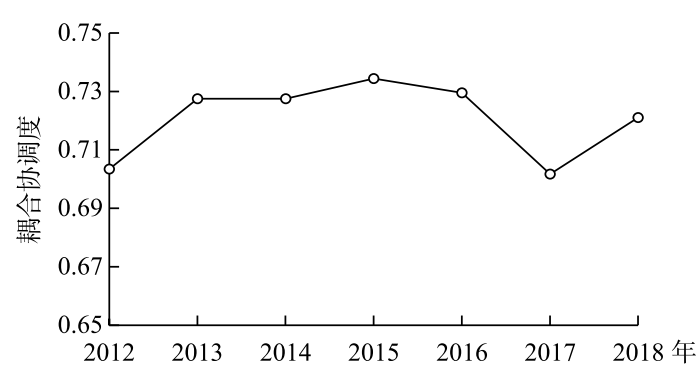

图 7 长江中游城市群 2012-2018 年 水资源承载系统的耦合协调度

Fig.7 Coordination degree of water resources carrying system in urban agglomeration in the middle reaches of the Yangtze River from 2012 to 2018

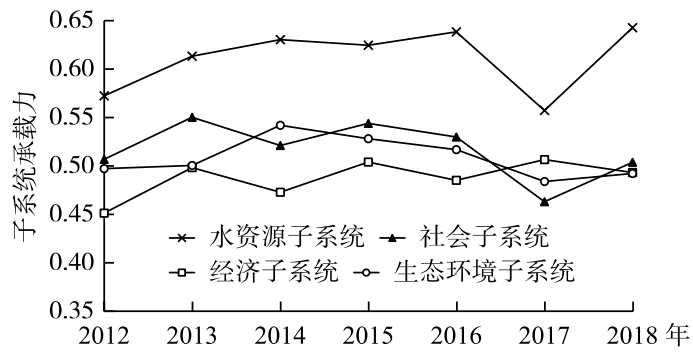

图 8 2012-2018 年各子系统承载力的评分

Fig. 8 Scores of carrying capacity for each subsystem from 2012 to 2018

过计算可得 28 个城市水资源承载力和耦合协调度 两组数据的相关系数为 0.98 , 说明水资源承载力与 耦合协调度有极强的正相关关系. 取各城市同一年 耦合协调度的算术平均值得到该年度的长江中游 城市群平均耦合协调度,如图 7 所示.

长江中游城市群水资源承载力子系统耦合协 调度呈先平稳上升、随后下降、再上升的变化趋势 (图 7), 与水资源承载力的变化趋势较为相似. 2012 年耦合协调度处于中等水平 $(0.703) ; 2013-2016$ 年处于较高水平, 2015 年达到峰值 (0.734).2017、 2018 年协调度跌至中等水平, 为探究协调度变化原 因,取各市的算数平均值得到水资源、社会、经济、 生态环境子系统 2012-2018 年承载力, 如图 8 所示.

2012-2016 年水资源子系统承载力呈上升趋 势, 社会子系统承载力呈波动下降趋势, 经济子系 统承载力在波动中缓步上升, 生态环境子系统承载 力 2014 年后逐年下降. 2017 年水资源子系统、社会 子系统承载力大幅下降, 造成协调度降低,但仍处 与协调度中等水平. 由图 3 可知水资源子系统内的 地表水资源占比(C2)、社会经济子系统内的人口自 然增长率 $(\mathrm{C} 8)$ 、人均耕地面积 (C12) 指标加权标准 化值在 2017 年下降明显, 导致该年份水资源子系统 承载力和社会经济子系统承载力下降,进而导致耦 合协调度的降低.

\section{4 讨论}

\section{1 水资源承载力关键影响因素}

取每个指标 2012-2018 年权重的算术平均值, 排名前 5 的指标分别是城市污水处理厂日处理能力 (C24)、人均 GDP (C14)、城镇化率 (C9)、第三产业比重 (C13) 和人均水资源量 (C1). 可见人类对水资源的 保护、社会经济活动和当地水资源禀赋对长江中游城市群水资源承载力有重要影响. 长江中游城市群水资 源承载力的研究主体以相关省份和内部小城市群居多,陆佳慧等 ${ }^{[51]}$ 基于随机森林算法对湖北省水资源承载 力进行了评价, 供水模数、需水模数、万元 GDP 排污量、日生活用水定额、水资源开发利用率是湖北省水资源 承载力的关键影响因子; 危文广等 ${ }^{[24]}$ 基于理想点法对江西省资源进行了评价,年降水量、工业用水重复利用 率、第三产业比重、人均水资源量、污水处理率对江西省的水资源承载力影响较大. 其中第三产业比重与本 文的结论吻合, 由于研究尺度和指标选取的不同, 部分关键指标与本文有差异, 但都主要体现在在水资源数 量和利用上. 田培等 ${ }^{[46]}$ 运用变权 TOPSIS 模型评价了长江经济带 2015-2017 年的水资源承载力, 发现湖北 省、湖南省、江西省水资源承载力 3 年间稳步增长, 而本文认为 2015-2017 年承载力逐年下降, 这可能与研 究尺度、权重确定方法和指标选取等差异有关.

\section{2 水资源承载系统耦合协调性}

Wang 等 ${ }^{[20]}$ 运用三系统耦合协调模型测算了湖南省各个地级市水资源、社会经济、生态环境系统间的耦 合协调度, 结果表明湖南省耦合协调度呈现东西北三面高, 中南部 (湘潭、衡阳、娄底) 低的空间分布特征. 本 文研究发现湘潭、衡阳处于耦合协调度中等水平, 娄底处于较低水平, 环长株潭城市群其他城市处于中等或 较高水平, 空间分布特征与该研究稍有不同. 该研究根据相关经济发展规划及相关专家学者咨询的结果, 为 
突出湖南省作为中部重要省份将经济建设放在较重要的位置,把水资源、社会经济、生态环境系统的待定系 数分别设为 $0.3 、 0.4 、 0.3$. 然而本文与其他协调度研究文献 ${ }^{[15,19,52]}$ 认为水资源、社会、经济、生态环境子系统 同等重要,各系统的待定系数相等. 在耦合协调度的计算中, 将各子系统视为同等重要是否忽略了区域特 征, 若有侧重又如何避免待定系数设置中主观性过强的问题有待深人研究. Zhu 等 ${ }^{[53]}$ 运用隶属函数协调模 型分析了长江中游城市群 2008-2017 年水资源与经济高质量发展的协调关系, 认为武汉、长沙、南昌和新余 的协调度持续处于较差水平; 而本研究表明武汉、长沙的耦合协调度处于极高水平, 南昌、新余处于较高水 平, 可能是由于研究方法和子系统数量不同所致. 另外, Zhu 等 ${ }^{[53]}$ 提出利用经济发展成果提高水资源利用效 率、改善水环境是促进长江中游城市群水资源与经济高质量发展相协调的关键, 本文也认为提高长江中游 城市群水资源承载力应注重经济发展过程中的技术创新.

\section{5 结论与建议}

本文综合考虑水资源一社会一经济一生态环境复合关系, 构建了水资源承载力评价指标体系, 运用改进 熵权 TOPSIS 模型、空间自相关和耦合协调发展模型, 定量评价了长江中游城市群发展战略实施前后 (2012-2018 年) 的水资源承载力时空格局及耦合协调性,主要结论如下：

1) 长江中游城市群整体的水资源承载力水平较高, 并呈先稳步上升 $(2012-2015$ 年)、后下降 (20152017 年)、再上升(2017-2018 年) 的波动变化趋势.

2) 2012-2018 年各城市间的水资源承载力差异不明显 (仅 2016 年差异显著), 且水资源承载力空间差 异性的变化特征随时间呈先缩小 (2012-2014 年)、后增大(2015-2016 年)、再缩小 (2017-2018 年) 的趋 势; 武汉城市圈水资源承载力呈现明显的低值包围高值的空间分布特征, 且其内部各城市水资源承载力的 差异较环长株潭城市群和环鄱阳湖城市群大.

3 ) 水资源子系统承载力水平最高 $(0.611)$, 经济子系统承载力水平最低 $(0.487)$, 社会子系统和生态环 境子系统承载力分别为 0.517 和 0.509 . 各城市的生态环境子系统承载力水平较高且较为均衡, 水资源子系 统、社会子系统、经济子系统的承载力差异较大.

4) 长江中游城市群水资源承载力各子系统间的耦合协调度总体处于中等水平, 3 个城市耦合协调度极 高、10 个城市较高、 7 个城市中等、 7 个城市较低、 1 个城市极低, 水资源承载力与耦合协调度之间有极强的 正相关关系.

长江中游城市群水资源承载力的提高需要通过新建、改建、扩建等方式提升污水处理厂的处理能力,推 进城镇污水处理设施建设. 合理控制城市经济社会发展规模和调整产业结构, 减少经济社会用水负担, 压缩 耗水量大、用水效益低、水污染严重的产业,提高工业用水重复率,逐步形成节水高效的产业体系. 全面推进 节水型社会建设, 形成以人水和谐为核心的节水型社会生产关系, 完善地方性水法规, 增强公众节水意识, 提高水资源利用效率.

\section{6 参考文献}

[ 1 ] Lv AF, Han Y, Zhang SF et al. The theory, method and practice of water resources carrying risk. China Water Resources, 2020, (19) : 47-51. [吕爱锋, 韩雁, 张士锋等. 水资源承载风险的理论、方法与实践. 中国水利, 2020, (19): 47-51.]

[ 2 ] Wang JH, Zhai ZL, Sang XF et al. Study on index system and judgment criterion of water resources carrying capacity. Journal of Hydraulic Engineering, 2017, 48(9) : 1023-1029. [王建华, 翟正丽, 桑学锋等. 水资源承载力指标体系 及评判准则研究. 水利学报, $2017, \mathbf{4 8}(9): 1023-1029$. ]

[ 3 ] Zuo QT. Review of research methods of water resources carrying capacity. Advances in Science and Technology of Water Resources, 2017, 37 (3) : 1-6, 54. [ 左其亭. 水资源承载力研究方法总结与再思考. 水利水电科技进展, 2017, 37 (3) : $1-6,54$.]

[ 4 ] Shi YF, Qu YG eds. Water resources carrying capacity and its rational utilization in the Urumqi River Basin. Beijing: Science Press, 1992. [施雅风, 曲耀光. 乌鲁木齐河流域水资源承载力及其合理利用. 北京: 科学出版社, 1992.]

[ 5 ] Zuo QT, Zhang XY. Dynamic carrying capacity of water resources under climate change. Journal of Hydraulic Engineering, 2015, 46(4) : 387-395. [ 左其亭, 张修宇. 气候变化下水资源动态承载力研究. 水利学报, 2015, 46 (4): 
387-395. ]

[ 6 ] Yao ZJ, Wang JH, Jiang D et al. Advances in study on regional water resources carrying capacity and research on its theory. Advances in Water Science, 2002, 13(1): 111-115. [姚治君, 王建华, 江东等. 区域水资源承载力的研究进展及 其理论探析. 水科学进展, 2002, 13(1): 111-115.]

[ 7 ] Hui YH, Jiang XH, Huang Q et al. On system dynamic simulation model of water resources bearing capacity in duality mode. Geographical Research, 2001, 20(2): 191-198. [ 惠泱河, 蒋晓辉, 黄强等. 二元模式下水资源承载力系统动 态仿真模型研究. 地理研究, 2001, 20(2): 191-198.]

[ 8 ] Duan CQ, Liu CM, Chen XN et al. Preliminary research on regional water resources carrying capacity conception and method. Acta Geographica Sinica, 2010, 65 (1) : 82-90. [段春青, 刘昌明, 陈晓楠等. 区域水资源承载力概念及研究 方法的探讨. 地理学报, 2010, 65(1): 82-90.]

[ 9 ] Wang H. Study on rational allocation of water resources in North-west China based on ecological consideration. Water Resources and Hydropower Engineering, 2006, 37(1) : 9-14. [王浩. 面向生态的西北地区水资源合理配置问题研究. 水 利水电技术, 2006, 37 (1): 9-14.]

[10] Li Y, Yang YZ, Yan HM et al. Research methods of water resources carrying capacity: Progress and prospects. Journal of Resources and Ecology, 2018, 9(5) : 455-460. DOI: 10.5814/j.issn.1674-764x.2018.04.001.

[11] Wang YX, Wang Y, Su XL et al. Evaluation of the comprehensive carrying capacity of interprovincial water resources in China and the spatial effect. Journal of Hydrology, 2019, 575: 794-809. DOI: 10.1016/j.jhydrol.2019.05.076.

[12] Wu CG, Zhou LY, Jin JL et al. Regional water resource carrying capacity evaluation based on multi-dimensional precondition cloud and risk matrix coupling model. Science of the Total Environment, 2020, 710: 136324. DOI: 10.1016/j.scitotenv.2019.136324.

[13] Fang HY, Gan SW, Xue CY. Evaluation of regional water resources carrying capacity based on binary index method and reduction index method. Water Science and Engineering, 2019, 12(4) : 263-273. DOI: 10.1016/j.wse.2019.12.008.

[14] Zhang LB, Hu YN, Jin JL et al. Dynamic prediction of water resources carrying capacity of Chaohu Basin and system optimization regulation based on system dynamics simulation. J Lake Sci, 2021, 33 (1) : 242-254. DOI: 10.18307/2021. 0106. [张礼兵, 胡亚南, 金菊良等. 基于系统动力学的巢湖流域水资源承载力动态预测与调控. 湖泊科学, 2021, 33(1) : 242-254.]

[15] Wang BQ, Yang H, Zhu Y. Comprehensive evaluation of water resource carrying capacity of Yangtze River economic zone. Resources \& Industries, 2020, 22(1): 1-11. [王保乾, 杨晖, 竺运. 长江经济带水资源承载力综合评价研究. 资源与 产业, 2020, 22(1): 1-11.]

[16] Yang XM, Yang TB, Shi PJ et al. Coupling effect of water resources-urbanization composite system in north west arid region of China: A case of Shiyang River Basin. Arid Land Geography, 2014, 37(1): 19-30. [杨雪梅, 杨太保, 石培基 等. 西北干旱地区水资源-城市化复合系统耦合效应研究——以石羊河流域为例. 干旱区地理, 2014, 37 (1): 19-30.]

[17] Tian JF, Wang BY, Wang SJ. Urban land use efficiency and its coupling relationship in the three provinces of northeast China. Scientia Geographica Sinica, 2019, 39(2) : 305-315. [田俊峰, 王彬燕, 王士君. 东北三省城市土地利用效益 评价及耦合协调关系研究. 地理科学, 2019, 39(2): 305-315.]

[18] Zhan YR, Gai M. Study on measurement and coordinated development of socio-ecological system resilience in coastal tourism destination. Areal Research and Development, 2018, 37(5) : 158-164. [展亚荣, 盖美. 滨海旅游地社会-生态系 统恢复力测度及协调发展研究. 地域研究与开发, 2018, 37(5) : 158-164.]

[19] Gai M, Nie C, Ke LN. Carrying capacity and coordinated development of ERE system in the coastal area of Bohai sea. Economic Geography, 2018, 38(7): 163-172. [盖美, 聂晨, 柯丽娜. 环渤海地区经济一资源一环境系统承载力及协调 发展. 经济地理, 2018, 38(7): 163-172.]

[20] Wang X, Dong Z, Xu W et al. Study on spatial and temporal distribution characteristics of coordinated development degree among regional water resources, social economy, and ecological environment systems. International Journal of Environmental Research and Public Health, 2019, 16(21): 4213. DOI: 10.3390/ijerph16214213.

[21] Xu JJ, Wu ZG. Discussion on idea and countermeasure of development and protection of Yangtze River water resources in new era. Yangtze River, 2020, 51 (1) : 124-128. [许继军, 吴志广. 新时代长江水资源开发保护思路与对策探讨. 人 民长江, 2020, 51(1): 124-128.]

[22] Jiang DC, Xiao WH, Fan CY et al. Research on water resources and water environment carrying capacities of Wuhan City 
circle. Resources and Environment in the Yangtze Basin, 2016, 25(5) : 761-768. DOI: 10.11870/cjlyzyyhj201605009. [姜大川, 肖伟华, 范晨媛等. 武汉城市圈水资源及水环境承载力分析. 长江流域资源与环境, 2016, 25(5): 761-768.]

[23] Xiong Y, Jiang N, Li JZ et al. Study on urban moderate scale of Changsha-Zhuzhou-Xiangtan urban agglomeration based on the water resources carrying. Economic Geography, 2016, 36(1): 75-81. [熊鹰, 姜妮, 李静芝等. 基于水资源承载 的长株潭城市群适度规模研究. 经济地理, 2016, 36(1) : 75-81.]

[24] Wei WG, Li LH, Lai JF et al. Evaluation of water resources carrying capacity in Jiangxi Province based on ideal point method. Journal of Water Resources and Water Engineering, 2018, 29(6) : 25-30. [危文广, 黎良辉, 赖敬飞等. 基于 理想点法的江西省水资源承载力评价. 水资源与水工程学报, 2018, 29(6): 25-30.]

[25] Song F, Yang XH, Wu FF. Catastrophe progression method based on M-K test and correlation analysis for assessing water resources carrying capacity in Hubei Province. Journal of Water and Climate Change, 2020, 11(2) : 556-567. DOI: 10. 2166/wcc.2018.114.

[26] Zhu LJ, Li XC, Bai YR et al. Evaluation of water resources carrying capacity and its obstruction factor analysis: A case study of Hubei Province, China. Water, 2019, 11(12) : 2573. DOI: 10.3390/w11122573.

[27] Zhang JR, Shi GQ. Study on the ecological carrying capacity of urban agglomerations in the middle reaches of the Yangtze River. Resources and Environment in the Yangtze Basin, 2020, 29(8)：1694-1702. [张津瑞, 施国庆. 长江中游城市群 生态承载力差异的比较研究. 长江流域资源与环境, 2020, 29(8): 1694-1702.]

[28] Shen W, Lu FX, Qin YC. Analysis of temporal-spatial patterns and influencing factors of urban ecosystem carrying capacity in urban agglomeration in the middle reaches of the Yangtze River. Acta Ecologica Sinica, 2019, 39(11): 3937-3951. DOI: 10.5846/stxb201810212274. [沈威, 鲁丰先, 秦耀辰等. 长江中游城市群城市生态承载力时空格局及其影响 因素. 生态学报, 2019, 39(11): 3937-3951.]

[29] Mao P, Lin AW, Yang Q et al. Evaluation of ecological carrying capacity based on state-space method in the urban agglomeration in the middle reach of Yangtze River. Geomatics \& Spatial Information Technology, 2017, 40(3) : 37-41. [毛 鹏，林爱文，杨倩等. 基于状态空间法的长江中游城市群区域生态承载力评价. 测绘与空间地理信息, 2017, 40 (3) : 37-41.]

[30] Li ZP, Ouyang Q. Evaluation and countermeasures of green development among urban agglomeration in the middle reaches of Yangtze River. Journal of Nantong University: Social Sciences Edition, 2017, 33(5) : 29-35. [李祝平, 欧阳强. 长江 中游城市群绿色化发展现状及对策. 南通大学学报: 社会科学版, 2017, 33(5): 29-35. ]

[31] Xiong X, Zhang T, Duan YJ et al. Measurement and comparison of the level of the green development about urban agglomeration in the middle reaches of the Yangtze River. Economic Geography, 2019, 39(12): 96-102. [熊犧, 张陶, 段宜嘉 等. 长江中游城市群绿色化发展水平测度及其差异. 经济地理, 2019, 39(12) : 96-102.]

[32] Yu HQ. Evaluation and comparative study on green development of three city groups in the Yangtze River economic zone [Dissertation]. Guiyang: Guizhou University of Finance and Economics, 2018. [于海奇. 长江经济带三大城市群绿色 发展评价与比较研究 [学位论文]. 贵阳: 贵州财经大学, 2018.]

[33] National Development and Reform Commission. Notice on the issuance of the "Development Plan for Triangle of Central China”. 2015. http://www.sdpc.gov.cn/zcfb/zcfbtz/201504/t20150416_688229.html. [中华人民共和国国家发展和 改革委员会. 关于印发《长江中游城市群发展规划》的通知. 2015.]

[34] Li H, Huang XJ, Jin YZ et al. Population carrying capacity of water resources in the Yangtze River economic belt. Economic Geography, 2017, 37(1) : 181-186. [李焕, 黄贤金, 金雨泽等. 长江经济带水资源人口承载力研究. 经济地 理, 2017, 37(1): 181-186.]

[35] Yang HY, Sun XB, Cheng XW et al. Comprehensive evaluation of water resources carrying capacity in Weifang based on the VIKOR method. Acta Scientiae Circumstantiae, 2020, 40(2) : 716-723. DOI: 10.13671/j.hjkxxb.2019.0344. [杨海 燕, 孙晓博, 程小文等. 基于 VIKOR 法的潍坊市水资源承载力综合评价. 环境科学学报, 2020, 40(2) : 716-723.]

[36] Zhang YB, Zhang JS. Comprehensive evaluation of water resources carrying capacity in Binzhou City in Shandong Province. Water Resources Development and Management, 2020, (12): 1-8. [张玉冰, 张锦水. 山东省滨州市水资源承载力综合 评价. 水资源开发与管理, 2020, (12): 1-8.]

[37] Liu YH, Li YB, Liang XY et al. Study on water resource carrying capacity evaluation and change in China. Resources and Environment in the Yangtze Basin, 2019, 28(5): 1080-1091. [刘雁慧, 李阳兵, 梁金源等. 中国水资源承载力评价 及变化研究. 长江流域资源与环境, 2019, 28(5): 1080-1091.] 
[38] Wang JH, Jiang DC, Xiao WH et al. Study on theoretical analysis of water resources carrying capacity : Definition and scientific topics. Journal of Hydraulic Engineering, 2017, 48(12) : 1399-1409. [王建华, 姜大川, 肖伟华等. 水资源承 载力理论基础探析 : 定义内涵与科学问题. 水利学报, 2017, 48(12) : 1399-1409.]

[39] Wang B, Teng YG, Wang HQ et al. Entropy weight method coupled with an improved DRASTIC model to evaluate the special vulnerability of groundwater in Songnen Plain, Northeastern China. Hydrology Research, 2020, 51( 5) : 1184-1200. DOI: $10.2166 /$ nh.2020.056.

[40] Zhou HC, Zhang GH, Wang GL. Multi-objective decision making approach based on entropy weights for reservoir flood control operation. Journal of Hydraulic Engineering, 2007, 38(1): 100-106. [周惠成, 张改红, 王国利. 基于熵权的 水库防洪调度多目标决策方法及应用. 水利学报, 2007, 38(1): 100-106.]

[41] Li YH, Zhou JZ. Modified entropy method and vague set based multi-objective flood control decision making approach. Water Resources and Power, 2010, 28 (6) : 32-35. [李英海, 周建中. 基于改进熵权和 Vague 集的多目标防洪调度决策 方法. 水电能源科学, $2010,28(6): 32-35$. ]

[42] Ouyang S, Shi YL. A new improved entropy method and its application in power quality evaluation. Automation of Electric Power Systems, 2013, 37(21) : 156-159,164. DOI: 10.7500/AEPS201210206. [欧阳森, 石怡理. 改进熵权法及其在 电能质量评估中的应用. 电力系统自动化, 2013, 37(21): 156-159,164.]

[43] Yang T, Zhang Q, Wan XH et al. Comprehensive ecological risk assessment for semi-arid basin based on conceptual model of risk response and improved TOPSIS model-a case study of Wei River Basin, China. Science of the Total Environment, 2020, 719: 137502. DOI: 10.1016/j.scitotenv.2020.137502.

[44] Liu D, Qi XC, Qiang F et al. A resilience evaluation method for a combined regional agricultural water and soil resource system based on Weighted Mahalanobis distance and a Gray-TOPSIS model. Journal of Cleaner Production, 2019, 229: 667-679. DOI: 10.1016/j.jclepro.2019.04.406.

[45] Lin LZ, Li D, Lin Z. Evaluation of water resources carrying capacity in Kubuqi Desert Area based on entropy weight and TOPSIS model. Journal of Central China Normal University: Natural Sciences, 2020, 54(4) : 640-648. [林龙圳, 李达, 林震. 基于熵权-TOPSIS 模型的库布齐沙漠地区水资源承载力评价. 华中师范大学学报: 自然科学版, 2020,54 (4) : 640-648.]

[46] Tian P, Zhang ZH, Xu XY et al. Comprehensive evaluation of water resources carrying capacity in the Yangtze River Economic Belt based on variable weight TOPSIS model. Journal of Central China Normal University: Natural Sciences, 2019, 53 (5) : 755-764. [田培, 张志好, 许新宜等. 基于变权 TOPSIS 模型的长江经济带水资源承载力综合评价. 华中师 范大学学报: 自然科学版, 2019, 53(5): 755-764.]

[47] He G, Xia YL, Qin Y et al. Evaluation and spatial-temporal dynamic change of water resources carrying capacity in the Yangtze River economic belt. Research of Soil and Water Conservation, 2019, 26( 1) : 287-292, 300. [何刚, 夏业领, 秦 勇等. 长江经济带水资源承载力评价及时空动态变化. 水土保持研究, 2019, 26(1) : 287-292, 300.]

[48] Zhang LQ, Fang YY. Study of spatial pattern of water resources ecological pressure in Anhui Province based on spatial autocorrelation analysis. Water Resources Protection, 2017, 33(1): 24-29. [张乐勤, 方宇媛. 基于空间自相关分析的安 徽省水资源生态压力空间格局探析. 水资源保护, 2017, 33(1) : 24-29.]

[49] Guo LR, Meng JJ, Li F. Water resources vulnerability in the middle reaches of Heihe River based on spatial heterogeneity. Journal of Arid Land Resources and Environment, 2018, 32(9) : 175-182. [郭力仁, 蒙吉军, 李枫. 基于空间异质性的 黑河中游水资源脆弱性研究. 干旱区资源与环境, 2018, 32(9) : 175-182.]

[50] Zhou JJ, Zhang M. Effect of dams on the regime of the mid-lower Yangtze River runoff and countermeasures. J Lake Sci, 2018, 30 (6) : 1471-1488. DOI : 10.18307/2018.0601. [ 周建军, 张曼. 近年长江中下游径流节律变化、效应与修复 对策. 湖泊科学, $2018, \mathbf{3 0}(6)$ : 1471-1488.]

[51] Lu JH. A assessment model of water resources carrying capacity based on random forest algorithm and its application in Hubei Province. Hubei Agricultural Sciences, 2020, 59(13) : 72-76. [ 陆佳慧. 基于随机森林算法的湖北省水资源承载力 评价模型及其应用. 湖北农业科学, 2020, 59(13): 72-76.]

[52] Geng YQ, Zhang H. Coordination assessment of environment and urbanization: Hunan case. Environmental Monitoring and Assessment, 2020, 192(10) : 1-18. DOI: 10.1007/s10661-020-08598-3.

[53] Zhu H, Zhu JS, Zou Q. Comprehensive analysis of coordination relationship between water resources environment and high-quality economic development in urban agglomeration in the middle reaches of Yangtze River. Water, 2020, 12(5): 1301. DOI: 10.3390/w12051301. 